\title{
IODP Drilling of the "Shackleton Sites" on the lberian Margin: A Plio-Pleistocene Marine Reference Section of Millennial-Scale Climate Change
}

\author{
by Fatima Abrantes, David Hodell, Gabriella Carrara, \\ Luis Batista, and Henrique Duarte
}

doi:10.2204/iodp.sd.9.10.2010

Few marine sediment cores have played such a pivotal role in paleoclimate research as those recovered from the Portuguese Margin, including MD95-2039 to MD95-2042 (hereafter referred to as the "Shackleton sites") (Fig. 1). These cores preserve a high-fidelity record of millennial-scale climate variability for the last several glacial cycles and can be readily correlated to Greenland ice cores. Moreover, the narrow continental shelf and proximity of the Tagus River results in rapid delivery of terrestrial material to the deep-sea environment, thereby permitting correlation of marine and ice-core records to European terrestrial sequences. Few places exist in the world's ocean where such marine-ice-terrestrial linkages are possible. Consequently, the Iberian Margin cores have become de facto reference sections for the study of abrupt climate change.

The seminal importance of these sections warrants investment by IODP to ensure that the entire Plio-Pleistocene record is continuously cored and properly recovered with multiple holes at several locations. To this end, we held a drilling workshop ("IODP Drilling of the "Shackleton sites' on the Iberian Margin: In Search of a Plio-Pleistocene Marine Reference Section") in Lisbon on 9-10 November 2009, sponsored by the European Science Foundation Workshops on Marine Research Drilling - MAGELLAN WORKSHOP SERIES, to formulate a drilling proposal to extend these remarkable sediment archives by drilling with the $R / V$ JOIDES Resolution $(J R)$. The objectives of the workshop were to assemble researchers who have worked on the Portuguese Margin, especially on the Shackleton sites, to provide a forum for invitees to summarize past work, to present new ideas and data, to identify unanswered key questions, and to discuss the best drilling strategy for reaching the overall goals.

We originally envisioned that the workshop would focus solely on paleoceanography, but during its organization
Portuguese and Italian colleagues of the tectonics community approached us. Their interest is to establish a borehole observatory (i.e., CORKed and instrumented hole) in the region of the fault, which is believed to have caused the devastating 1755 Lisbon earthquake and tsunami. Given the societal relevance and importance of these geohazards, we invited seven scientists with tectonic interests to attend the workshop and provide input for potential collaborative drilling to achieve both paleoceanographic and tectonic objectives.

Key paleoceanographic questions that emerged from the workshop including the following. (1) Was the bipolar seesaw a persistent feature of Earth's climate system, or did interhemispheric coupling differ for previous glacial periods? (2) How did millennial-scale variability "evolve" as glacial and orbital boundary conditions changed during the Pleistocene? (3) Did millennial-scale climate variability change in frequency or amplitude across the mid-Pleistocene transition ( $920 \mathrm{ka}$ and $640 \mathrm{ka})$, when the average climate state evolved toward generally colder conditions with larger ice sheets, and the spectral character of climate variability shifted from dominantly $41 \mathrm{kyr}$ to $100 \mathrm{kyr}$ ? (4) How do millennial and orbital bands of climate variability interact? (5) What role do millennial-scale events play in triggering glacial terminations? Only by integrating marine and ice-core stratigraphies can we begin to address mechanisms of the coupled ocean-atmosphere system, including the causes of Dansgaard-Oeschger variability, glacial-interglacial cycles, and atmospheric $\mathrm{CO}_{2}$ variation.

In an effort to address the paleoceanographic questions in a meaningful way, workshop participants discussed the suggestion by Alley (2003) that "paleoceanographers should consider following the ice-core community's lead and organize a research effort to generate a few internationally coordinated, multiply replicated, multiparameter, high time resolution-type sections of oceanic change." The group

Table 1. Location of proposed drilling site locations.

\begin{tabular}{|c|c|c|c|c|l|}
\hline Site & Lat $(\mathrm{N})$ & Long $(\mathrm{W})$ & Depth $(\mathrm{m})$ & Distance to land $(\mathrm{km})$ & \multicolumn{1}{c|}{ Objectives } \\
\hline 1A & $37^{\circ} 52,1$ & $10^{\circ} 12,6$ & 2978 & 123.4 & Plio-Quaternary Sequence with $\pm 700 \mathrm{~m}$ \\
\hline 2A & $37^{\circ} 48,45$ & $9^{\circ} 50,35$ & 2266 & 91 & Plio-Quaternary Sequence with $750-1000 \mathrm{~m}$ \\
\hline 3A & $37^{\circ} 45,5$ & $10^{\circ} 02,0$ & 2619 & 108 & Plio-Quaternary Sequence with $400-700 \mathrm{~m}$ \\
\hline 4A & $37^{\circ} 33,1$ & $10^{\circ} 08,8$ & 2658 & 118 & Plio-Quaternary Sequence with $400-800 \mathrm{~m}$ \\
\hline 5A & $37^{\circ} 32,8$ & $10^{\circ} 22,2$ & 3559 & 140 & Plio-Quaternary Sequence with $400-800 \mathrm{~m}$ \\
\hline
\end{tabular}


suported such an approach and proposed that IODP drilling of the Portuguese Margin could serve as a "proof of concept" for adopting an integrated strategy for sampling and analyzing IODP cores that emphasizes a truly multiproxy approach with attention to resolution, replication, and time control. As a way forward we identified five potential drilling sites in a range of water depths that target sections with the greatest possible sedimentation rates for all time periods of interest and offer the opportunity to obtain continuous sequen-ces that are undisturbedby downslope transport (Fig. 1). In anticipation of the high sample demand for these reference sections, we would plan to drill many holes (up to six) per site to produce multiple copies of composite sections for short- and long-term sampling requests.

In addition to the paleoceanographic questions, a number of tectonics-related questions were generated by the workshop, including: (1) What is the recurrence interval of potential destructive earthquakes and tsunami? (2) What is the rheology of the area? (3) What are the interactions between fluid pressure variation and fault kinematics? Addressing these questions is vital for understanding and mitigating geohazards in this region. As the state of "drilling readiness" for the two sets of objectives is quite different and issues with the borehole observatory site will require additional time to resolve, workshop participants opted to prepare separate but parallel drilling proposals.

The first proposal is to drill the marine-type sections of millennial variability for the last several glacial cycles, known as "Shackleton sites" (to be submitted 1 April 2010). The second is a pre-proposal to address the important geohazards/tectonic concerns of this seismic region (to be submitted in either April or October 2010).

\section{References}

Alley, R.B., 2003. Raising paleoceanography. Paleoceanogr., 18(44):1085, doi 10.1029/2003PA000942.

\section{Authors}

Fatima Abrantes, Gabriella Carrara, Luis Batista, and Henrique Duarte, Laboratório Nacional de Energia e Geologia (LNEG), I.P. Estrada da Portela, Bairro do Zambujal - Alfragide Apartado 7586 - 2720-866 Amadora, Portugal, e-mail: fatima.abrantes@ineti.pt.

David Hodell, University of Cambridge - Department of Earth Sciences, Cambridge, U.K., e-mail: dhod07@esc.cam. ac.uk.

\section{Related Web Link}

http://www.esf.org > Shackleton > Past Science Meetings 